Мобільні і стаціонарні енергозасоби та їх елементи Mobile and stationary power units and their elements

УДК 504.05

https://doi.org/10.37700/enm.2020.2(16).12 - 18

\title{
Інформаційна комплексна система діагностики гібридних і електромобілів
}

\author{
О.В. Бажинов ${ }^{1}$, Р.P. Заверуха ${ }^{2}$, Т.О. Бажинова ${ }^{3}$ \\ ${ }^{1}$ Харківський національний автомобільно-дорожній університет, \\ (м. Харків, Україна) email: alexey.bazhinov@gmail.com, ORCID: 0000-0002-5755-8553 \\ 2 Тернопільський національний технічний університет імені Івана Пулюя, \\ (м. Тернопіль, Україна) еmail: ruslan.zaveruha@email.ua, ORCID: 0000-0001-6108-4023 \\ ${ }^{3}$ Харківський національний технічний університет сільського господарства \\ імені Петра Василенка, (м. Харків, Україна) \\ email: tatyana2882@gmail.com,ORCID:0000-0003-3003-4028
}

\begin{abstract}
Розглянуто штучні нейроні мережі в системі управління силовою установкою транспортного засобу з метою зменшення витрати енергії та діагностики off-line технічного стану тягової акумуляторної батареї. Отримано метод діагностики технічного стану силової установки, який використовує штучні нейронні мережі та системи нечіткого висновку для визначення технічного стану ДВЗ та тягової акумуляторної батареї.

Метою роботи є підвищення ефективності діагностики функціональних систем гібридного та електромобіля шляхом оперативного синтезу управляючих впливів за енергетичними і якісними критеріями з урахуванням зовнішніх умов експлуатації. Обґрунтування методу діагностики технічного стану силової установки гібридного та електромобіля з використанням штучної нейронної мережі та системи нечіткого висновку. Дати наукове обґрунтування діагностичних параметрів силової установки гібридного автомобіля. В роботі використано штучні нейронні мережі в системі управління силовою установкою транспортного засобу з метою зменшення витрати енергії та діагностики off-line технічного стану тягової акумуляторної батареї. За допомогою симулятора навчається нейромережева модель автомобіля, яка використовує off-line навчання нейроконтролера. Якість навчання нейроконтролера визначається симулятором. При подальшому функціонуванні системи управління параметри нейронних мереж не змінюються. Відсутність адаптації вагових коефіцієнтів при функціюванні системи управління обґрунтовано тим, що це веде до втрати довго часової пам'яті системи управління при виникненні кратко часової несправності, а також можливості виникнення біфуркації при адаптації в нелінійних системах наведено на рисунку 1.

Цільова функція оптимізації управління має на увазі мінімізацію витрати енергії при збереженні ступеню заряду тягової акумуляторної батареї при обмеженому діапазоні руху транспортного засобу в заданих умовах експлуатації.

За результатами випробувань метода нейроуправління отримано, що нейроконтролер забезпечує зменшення витрати палива на 17 \% і скорочує діапазон зміни ступеня зарядженості тягової акумуляторної батареї на 35 \%, а також забезпечує мінімізацію викидів токсичних речовин.
\end{abstract}

Ключові слова: електрична силова установка, гібридний автомобіль, технічний стан, штучна нейронна мережа, акумуляторна батарея, діагностика.

Вступ. Сучасний стан розвитку і оновлення структури гібридних та електромобілів, які експлуатуються в умовах України, зумовлюють необхідність комплексного підходу до оцінки технічного стану з метою вибору найкращої технології діагностування силової установки. Діагностування, ремонт силової установки гібридних та електромобілів є проблемою. Оскільки, силова установка в сукупності з електронними блоками управління та іншими вузлами мають складну систему, яка потребує спеціальних підходів при діагностиці технічного стану та ремонті.

Аналіз публікацій. В управлінні силовими установками гібридних та електромобілів використовуються методи розрахункового інтелекту [1, 2]. Управління на підставі нечітких правил і систем нечіткого виводу використовується в роботах $[3,4]$, а в роботах $[5,6]$ досліджується можливість 
використання генетичних алгоритмів для налагоджування систем нечіткого висновку.

Використання штучних нейронних мереж (ШНМ) при управління силової установки наведено в роботах $[7,8]$. Сумісному використанню ШНМ та систем нечіткого виводу присвячені роботи [9, 10]. Наведені дослідження вказують на значний потенціал покращення експлуатаційних характеристик гібридних та електромобілів на підставі ефективного управління потужністю при використанні технологій штучного інтелекту.

$€$ три підходи до будови силових установок гібридних та електромобілів, які відрізняються принципами реалізації стратегії управління при вирішені другого рівня ієрархії. Це використання логічних правил вибору стратегії, або використання методів теорії оптимального управління та використання алгоритмів адаптації до зовнішніх умов експлуатації гібридних та електромобілів. На практиці поширеним є вибір стратегії управління силовою установкою на підставі логічних правил та табличне задання законів регулювання $[11,12]$.

Правила та закони управління встановлюють розробники силових установок шляхом використання евристичних методів і аналізу результатів штучного інтелекту. В даному випадку не враховуються особливості конкретних умов експлуатації, які впливають на ефективність роботи силової установки. Отже, такий підхід не дозволяє використовувати в повній мірі енергоефективність силової установки. Якщо стратегія управління не відповідає зовнішнім умовам роботи автомобіля то силова установка може мати гірші показники енергетичної економічності та токсичності відпрацьованих газів в порівнянні з базовим автомобілем.

Мета й визначення завдання. Метою роботи $€$ підвищення ефективності діагностики функціональних систем гібридного та електромобіля шляхом оперативного синтезу управляючих впливів за енергетичними і якісними критеріями 3 урахуванням зовнішніх умов експлуатації. Обґрунтування методу діагностики технічного стану силової установки гібридного та електромобіля 3 використанням штучної нейронної мережі та системи нечіткого висновку. Надати наукове обґрунтування діагностичних параметрів силової установки гібридного автомобіля.

Вирішення завдання. Логіка функціонування силової установки може задаватися за допомогою бази нечітких правил та використовувати систему нечіткого висновку. Також для апроксимації законів регулювання або характеристик агрегатів використовується інтелектуальна нейрона мережа (IHM).

Принцип управління на підставі логічних правил використовується в силових установках більшості гібридних та електромобілів. В роботі використано штучні нейроні мережі в системі управління силовою установкою транспортного засобу 3 метою зменшення витрати енергії та діагностики off-line технічного стану тягової акумуляторної батареї. За допомогою симулятора навчається непромережена модель автомобіля, яка використовує для off-line навчання нейроконтролера. Якість навчання нейроконтролера визначається симулятором. Для подальшому функціонуванні системи управління параметри нейронних мереж не змінюються. Відсутність адаптації вагових коефіцієнтів при функціонуванні системи управління обґрунтовано тим, що це веде до втрати довго часової пам'яті системи при виникненні кратко часової несправності, а також можливості виникнення біфуркацій при адаптації в нелінійних системах наведено на рисунку 1.

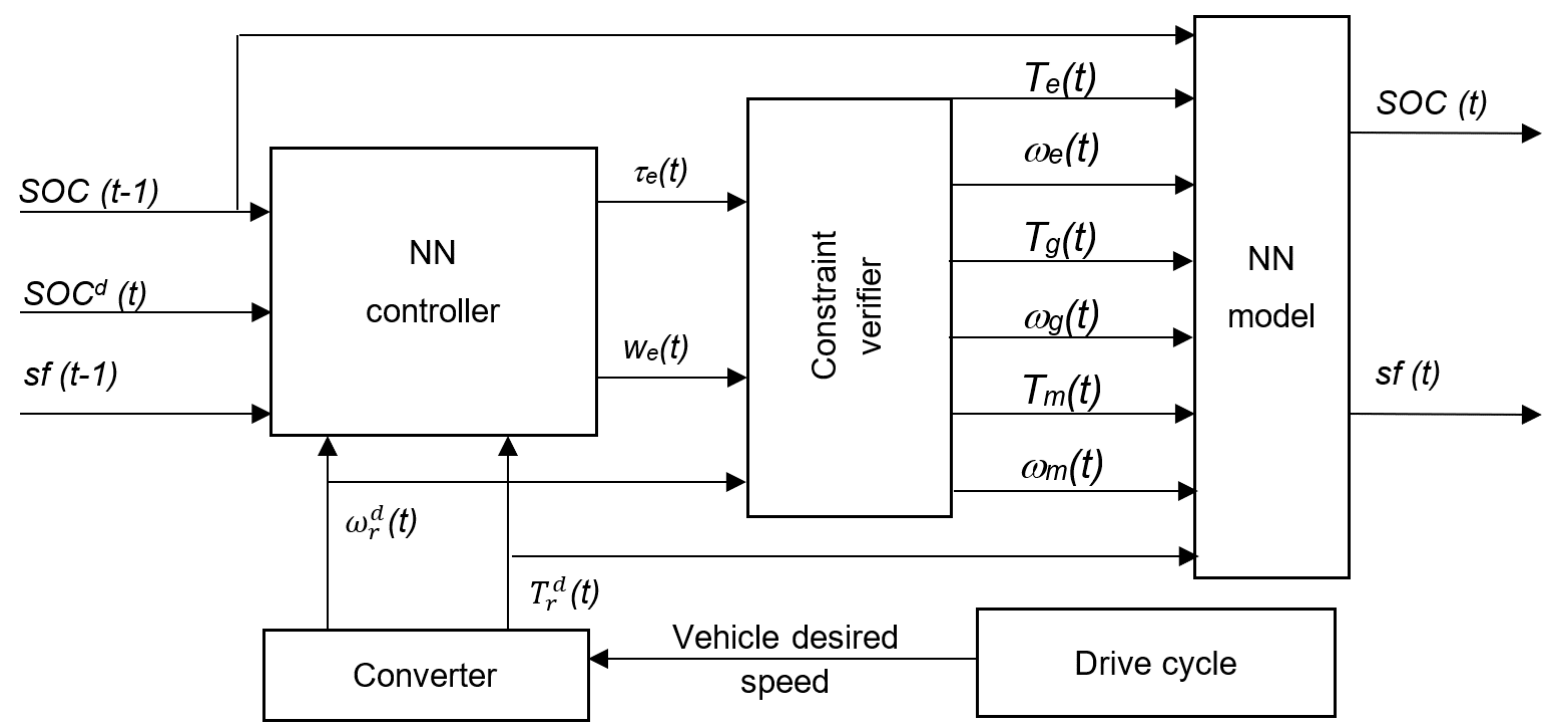

Рис. 1 Навчання нейроконтролера

Інженерія природокористування, 2020, №2(16), с. 12 - 18 Engineering of nature management, 2020, \#2(16), p. 12 - 18 
Цільова функція оптимізації управління має на увазі мінімізацію витрати енергії при збережені ступеню заряду тягової акумуляторної батареї при обмеженому діапазоні руху транспортного засобу в заданих умовах експлуатації

$$
\cos t(t)=\lambda_{1} \cdot s f^{2}(r)+\lambda_{2}\left(\operatorname{SOC}^{d}(t)-\operatorname{SOC}(t)\right)^{2}
$$

де $\lambda_{1}=1$ і $\lambda_{2}$ - вагові коефіцієнти, $\lambda_{2}=10$, при $S O C \geq S O C^{d}$ і $\lambda_{2}=50$ при $S O C\left\langle S O C C^{d}\right.$ sf - рівень витрати енергії (fuel rate); $S O C^{d}$ - бажана ступінь зарядженості тягової акумуляторної батареї.

Нейроконтролер (NN controller) має тришаровий рекурсивний персептрон з п'ятьма входами, 10 нейронів в закритому слої та два вихідних нейрона. В кожний момент часу $t$ на вхід нейронної межі подається п'яти компонентний вектор $\left[w_{r}^{r}(t), T_{t}^{r}(t), s f(t-1), S O C_{t}^{d}, S_{O} C^{d}(t-1)\right]$. На підставі даного вхідного вектору нейронна мережа визначає нормовані значення крутного моменту і швидкості обертання валу двигуна, які потім перетворюють в реальні сигнали управління силовою установкою в блоці Constraint verifier.

Процес навчання непромереженої моделі i нейроконтролера розглядається як задача оптимальної фільтрації з використанням фільтра Калмана. Вагові коефіцієнти нейронної мережі представлені як вектор стану динамічної системи. Нейромережева модель навчається протягом 3000 епох на масиві даних, які мають пари сигналів вхід-вихід від 20 різних умов роботи силової установки, генеруючих симулятором. Навчання нейроконтролера ведеться протягом 1200 епох.

За результатами випробувань метода нейроуправління отримано, що нейроконтролер забезпечує зменшення витрати палива на $17 \%$ і скорочує діапазон зміни ступеня зарядженості тягової акумуляторної батареї на 35 \%, а також забезпечує мінімізацію викидів токсичних речовин. Для поліпшення експлуатаційних характеристик силової установки слід використовувати цільову функцію оптимізації нейроконтролера параметрів в наявному вигляді. Недоліком методу слід визнати відсутність адаптації стратегії управління до зміни режиму руху.

Під інфрормаційною системою (IC) будемо розуміти впорядковану організаційно і взаємопов'язану сукупність програмно-технічних засобів і методів, які використовують сучасні інформаційні технології, і застосовуваних для збору, обробки, зберігання, відображення і передачі інформації 3 метою вирішення поставлених завдань.

Інформаційна система в автотранспортних засобах застосовується в якості основних технічних засобів переробки інформації та засобів зв'язку, що дозволяють реалізувати різні інформаційні процеси і висновок інформації, необхідної при прийнятті рішень в задачах будь-якої складності і для різних предметних областей.

Інформаційна система являє собою особливе середовище, що включає сукупність використовуваних комп'ютерів, локальних і глобальних комп'ютерних мереж зв'язку, програмних продуктів і інструментальних засобів їх розробки, баз даних, користувачів, інших різних технічних засобів підтримки інформаційних технологій та ін. В рамках класифікації IC можна виділити два основні класи систем: інформаційно-вимірювальні та інформаційно-керуючі системи.

Інформаційно-вимірювальна система (IBC) являє собою комплекс вимірювального обладнання, пристроїв обробки та передачі даних, що забезпечують автоматичний збір інформації, яка вимірюється кількісно, безпосередньо від досліджуваних автомобілів - за допомогою процедур вимірювання та контролю, аналізу і обробки інформації, а також відображення її у вигляді числових даних, висловлювань, графріків, таблиць, діаграм та інші, що відображають стану автомобілі.

Інформаційно-вимірювальна система - це «сукупність функціонально об'єднаних вимірювальних, обчислювальних та інших допоміжних технічних засобів, для отримання вимірювальної інформації, її перетворення, обробки з метою представлення споживачеві (в тому числі для введення в інформаційно-керуючу систему) в необхідному вигляді, або автоматичного здійснення логічних функцій контролю, діагностики, ідентифрікації».

Під інфрормаційно-керуючою системою (IКC) будемо розуміти певну сукупність програмно-апаратного комплексу засобів, методів, алгоритмів автоматизації інформаційних процесів моніторингу та реалізації керуючих впливів гібридними автомобілями.

Виділимо наступні основні компоненти інформаційно-керуючої системи:

- людський фрактор (аналітики, розробники, програмісти, користувачі, консультанти, інженери, лаборанти, техніки);

- інструментальні засоби розробки програмного забезпечення;

- системне і прикладне програмне забезпечення; - математичне та методологічне забезпечення;

- апаратне забезпечення;

- інформаційні технології.

Основна концепція інтелектуального транспортного засобу полягає в його здатності постійно контролювати дії водія, автомобіль і навколишнє середовище, а також допомагати водієві ефективно і безпечно керувати. Зараз велика увага приділяється проблемі ефективного використання енергетичних витрат електричною силовою установкою автомобілів в залежності від зовнішніх умов. Останнім часом основна увага зосереджена на вдосконалені технічних можливостей транспортного засобу. 
Електронні системи транспортних засобів виконують функцію закритих систем, оскільки отримують інформацію від різних датчиків транспортного засобу і аналізують їі за допомогою програм та виконують в електронному блоці управління (ЕБУ) відповідні команди виконавчим пристроям 3 метою підвищення ефективності фрункціонування електричної силової установки автомобіля. Взаємодія між електронними блоками управління виконується завдяки шинним архітектурам, які представляють сукупність контролерів (CAN), а також спеціальну мережу, призначену для передачі інформації спеціального цифрового обладнання - MOST, mediaoriented systems trans, Flex Ray, а також Local interconnect, (LIN).

Системне програмне забезпечення, яке керує гібридним автомобілем і електромобілем, наведено на рис. 2 і складається $з$ таких основних підсистем: сприйняття, планування місій, здійсненої поведінки і планування руху. Ці підсистеми складаються з декількох процесів і передачі повідомлень відповідно до обраної топології.

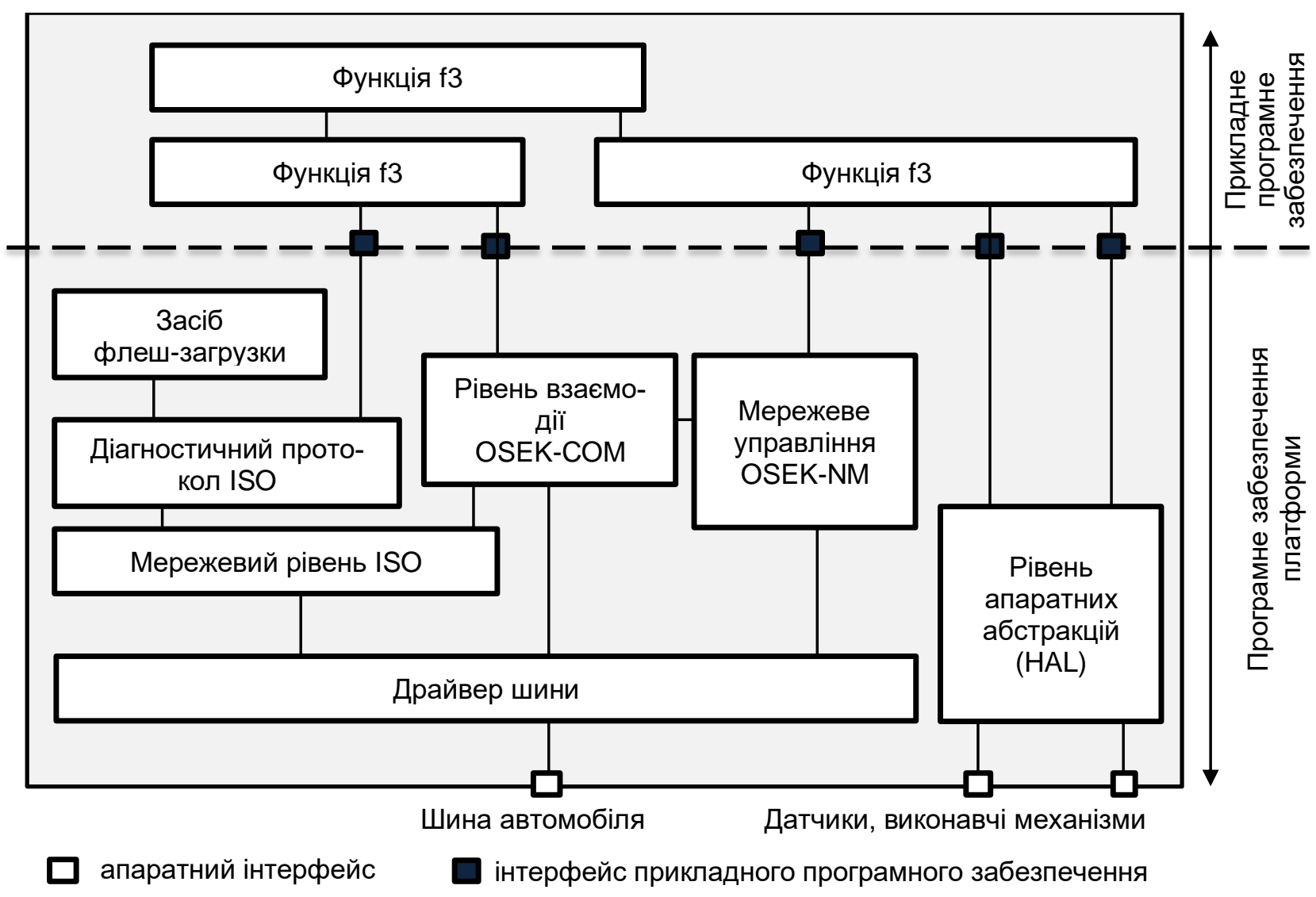

Рис. 2. Загальна архітектура системи, яка включає основні підсистеми та канали передачі даних

Програмне забезпечення в електромобілі складається з безліч компонентів, яке залежить від апаратної частини. Взаємодія між усіма функціями визначається в архітектурі і має різні відображення. Статичне відображення ієрархічно описує функціональні групи, сигнали і розподіл ресурсів. Динамічне відображення аналізує відгук при виконанні різних завдань. Найбільш важливі стандарти наведено нижче.

Асоціація стандартизації автоматизованих і вимірювальних систем (ASAM) займається стандартизацією в автомобільній промисловості стосовно моделям даних, інтерфейсів і синтаксису. ASAM розробила різні стандарти для підключення ЕБУ до комп'ютера введення даних.
Стандарт ASAM-MCD1 (MCD - вимір, калібрування та діагностика) підтримує протоколи передачі даних. Стандарт відображає відповідні дані у вигляді фрізичних значень і одночасно обробляє їx, а також дозволяє автоматично калібрувати дані і регламентувати обмін функціональними описами та даними.

Консорціум Flex Ray розробив специфікацію для польової шини для регулювання по розімкненому і замкнутому циклу транспортних засобів. Завдяки високій швидкості передачі даних із запрограмованим арбітражем шини і відмостійкості конструкції активно використовується в системах активної безпеки і в силових системах гібридних автомобілів. 
Зауважимо, що система керування силовою установкою гібридного і електромобіля має низку характерних особливостей, що вимагають організації і проведення досліджень з метою забезпечення можливості застосування готових програмних продуктів. Відомі системи AUTO SAR здатні вирішувати питання автоматизації процесу створення програмного забезпечення для розроблюваних систем управління. Однак, в технічній документації до цих систем немає відомостей про методи та алгоритми, що дозволяють в реальному масштабі часу синтезувати енерго- і ресурсозберігаюче управління силовими установками.

Висновки. Створювані інформаційні системи управління силовими установками повинні мати здатність до управління за різними критеріями, що забезпечує енерго- і ресурсозбереження, а також високу безпеку транспортного процесу без зниження якості гібридних автомобілів. Перераховані вимоги надають суперечливі впливу на завдання управління. Одночасне їх використання істотно ускладнює математичне і методологічне забезпечення проектованої системи управління, а також її технічну реалізацію.

Рішення задач управління по комплексному критерію недостатньо розглянуто в літературі, тому створення ІКС діагностування силових установок гібридних автомобілів за комплексними критеріями є своєчасною і актуальною задачею.

\section{Література}

1. Бажинова Т.О. Інтелектуальна інформаційно-керувальна система гібридних та електромобілів. Вісник ХНАДУ: зб. наук. пр. 2019. Вип. 86. с. $148-155$.

2. Мигаль В.Д. Інтелектуальні системи в технічній експлуатації автомобілів: монографія / В.Д. Мигаль. - Х.: «Майдан», 2018. - 262 с

3. Zhang Yi, Liu Heping, Wang Huabin . Torque Control Strategy for Parallel Hybrid Electric Vehicles using Fuzzy Logic/ WSEAS Transactions on Systems, iss. 4, vol. 10. - 2011. - P. 116-125.

4. Сєріков с.А. Нейромережеве управління гібридною силовою установкою на підставі методу адаптивної критики / с.А. Сєріков // Автомобільний транспорт. - 2012. - №30. - с.65 - 74.

5. Prajwowski K., Osipowicz T. Hybrid vehicle diagnostics //Journal of KONES. - 2017. - T. 24. №. 1. - с. 309 - 315 .

6. Руденко О.Г. Штучні нейронні мережі / О. Г. Руденко, Е. В. Бодянський // Навчальний посібник. - Харків: ООО « Компанія СМІТ», 2005. - 408 с.

7. Denton T. Electric and hybrid vehicles.Second edition: Institute of the motor industry. Routledge, 2020. 210 c.

8. Сараєв П.В. Багатошагове оптимальне нейромережеве управління / П. В. Сараєв // Проблеми управління. - 2008. - №5. - с. 14 - 18.
9. Короблев Н.М. Синтез нейромережевого нечіткого регулятора адаптивної системи управління динамічним об'ектом / Н.М. Короблев, А.Є. Макагон, О.Г. Лєбєдєв // Системи управління навігації та зв'язку, 2010. - Вип. 4 (16). - с. 119 - 123.

10. Мигаль В.Д. Мехатронні та телематичні системи автомобіля: навч. посіб. / В.Д. Мигаль. Х.: Вид-во Майдан, 2017. - 313 с.

11. Бажинова Т.О., Борисенко А.О. Експлуатаційні властивості гібридних автомобілів: монографрія. Х.: ФОП Бровін О.В., 2016. - 104 с.

12. Синергетичний автомобіль. Теорія і практика/ Бажинов О.В., Смирнов О. П.,Сєріков с.А. та ін. Х.: ХНАДУ, 2008. 327 c.

\section{References}

1. Bazhynova, T., 2019. Intelektualna informatsiino-keruvalna systema hibrydnykh ta elektromobiliv. Visnyk KhNADU, 86, pp.148 - 155.

2. Myhal, V., 2020. Intelektualni Systemy V Tekhnichnii Ekspluatatsii Avtomobiliv. Kharkiv: Maidan, p.262.

3. Alipour, H., Asaei, B. and Farivar, G., 2012. Fuzzy Logic Based Power Management Strategy for Plug-in Hybrid Electric Vehicles with Parallel Configuration. Renewable Energy and Power Quality, pp.1235 - 1239.

4. Sierikov, S., 2012. Neiromerezheve upravlinnia hibrydnoiu sylovoiu ustanovkoiu na pidstavi metodu adaptyvnoi krytyky. Avtomobilnyi transport, 30, pp.65-74.

5. Prajwowski, K. and Osipowicz, T., 2017. Hybrid vehicle diagnostics. Journal of KONES, 24(1), pp.305 - 315.

6. Rudenko, O. and Bodianskyi, E., 2005. Shtuchni Neironni Merezhi. Kharkiv: OOO « Kompaniia SMIT», p.408.

7. Denton, T., 2020. Electric And Hybrid Vehicles. 2nd ed. Routledge: Institute of the motor industry, p.210.

8. Saraiev, P., 2008. Bahatoshahove optymalne neiromerezheve upravlinnia. Problemy upravlinnia, (5), pp.14 - 18.

9. Koroblev, N., Makahon, A. and Liebiediev, O., 2010. Syntez neiromerezhevoho nechitkoho rehuliatora adaptyvnoi systemy upravlinnia dynamichnym obektom. Systemy upravlinnia navihatsii ta zviazku, 4(16), pp.119 - 123.

10.Myhal, V., 2017. Mekhatronni Ta Telematychni Systemy Avtomobilia. Kharkiv: Maidan, p.313.

11.Bazhynova, T. and Borysenko, A., 2016. Ekspluatatsiini Vlastyvosti Hibrydnykh Avtomobiliv. Kharkiv: FOP Brovin O.V., p.104.

12.Bazhynov, O., Smyrnov, O. and Sierikov, S., 2008. Synerhetychnyi Avtomobil. Teoriia I Praktyka. Kharkiv: KhNADU, p.327. 


\title{
Анотация \\ Информационная комплексная система диагностики гибридных и электромобилей
}

\author{
О.В. Бажинов, Р.Р. Заверуха, Т.О. Бажинов
}

Рассмотрены искусственные нейронные сети в системе управления силовой установкой транспортного средства с целью уменьшения расхода энергии и диагностики off-line технического состояния тяговой аккумуляторной батареи. Получено метод диагностики технического состояния силовой установки, который использует искусственные нейронные сети и системы нечеткого вывода для определения технического состояния ДВС и тяговой аккумуляторной батареи.

Целью работы является повышение эффективности диагностики функциональных систем гибридного и электромобиля путем оперативного синтеза управляющих воздействий по энергетическим и качественным критериям с учетом внешних условий эксплуатации. Обоснование метода диагностики технического состояния силовой установки гибридного и электромобиля с использованием искусственной нейронной сети, и системы нечеткого вывода. Дать научное обоснование диагностических параметров силовой установки гибридного автомобиля. В работе использованы искусственные нейронные сети в системе управления силовой установкой транспортного средства с целью уменьшения расхода энергии и диагностики off-line технического состояния тяговой аккумуляторной батареи. С помощью симулятора обучается нейросетевая модель автомобиля, которая использует оff-line обучение нейроконтролера. Качество обучения нейроконтролера определяется симулятором. При дальнейшем функционировании системы управления параметры нейронных сетей не меняются. Отсутствие адаптации весовых коэффициентов при функционировании системы управления обоснованно тем, что это ведет к потере долго временной памяти системы управления при возникновении кратко временной неисправности, а также возможности возникновения бифуркации при адаптации в нелинейных системах.

Целевая функция оптимизации управления подразумевает минимизацию расхода энергии при сохранении степени заряда тяговой аккумуляторной батареи при ограниченном диапазоне движения транспортного средства в заданных условиях эксплуатации.

По результатам испытаний метода нейроуправления получено, что нейроконтролер обеспечивает уменьшение расхода топлива на 17 \% и сокращает диапазон изменения степени заряженности тяговой аккумуляторной батареи на 35 \%, а также обеспечивает минимизацию выбросов токсичных веществ.

Ключевые слова: электрическая силовая установка, гибридный автомобиль, техническое состояние, искусственная нейронная сеть, аккумуляторная батарея, диагностика.

\section{Abstract \\ Information complex diagnostic system for hybrid and electric vehicles}

\section{O.V. Bazhinov, R.R. Zaverukha, T.O. Bazhynova}

Artificial neural networks in the control system of the power plant of the vehicle are considered in order to reduce energy consumption and diagnose the off-line technical condition of the traction battery. A method for diagnosing the technical state of a power plant has been obtained, which uses artificial neural networks and fuzzy inference systems to determine the technical state of an internal combustion engine and a traction battery.

The aim of the work is to increase the efficiency of diagnostics of functional systems of a hybrid and an electric vehicle by prompt synthesis of control actions according to energy and quality criteria, taking into account external operating conditions. Substantiation of the method for diagnosing the technical condition of the power plant of a hybrid and electric vehicle using an artificial neural network and a fuzzy inference system. Give a scientific basis for the diagnostic parameters of the power plant of a hybrid vehicle. In the work, artificial neural networks were used in the control system of the power plant of the vehicle in order to reduce energy consumption and diagnose the off-line technical condition of the traction battery. With the help of the simulator, an unmeasured car model is learned, which uses off-line training of the neurocontroller. The quality of the neurocontroller training is determined by the simulator. With the further functioning of the control system, the parameters of the neural networks do not change. The lack of adaptation of weight coefficients during the operation of the control system is justified by the fact that this leads to the loss of long-term memory of the control system when a short-term malfunction occurs, as well as the possibility of bifurcation during adaptation in nonlinear systems are shown in Figure 1.

ISSN 2311-1828

http://enm.khntusg.com.ua
Інженерія природокористування, 2020, №2(16), с. 12 - 18

Engineering of nature management, 2020, \#2(16), p. 12 - 18 
The target function of optimization of control implies minimization of energy consumption while maintaining the state of charge of the traction battery with a limited range of motion of the vehicle under given operating conditions.

Based on the results of tests of the neurocontroller method, it was found that the neurocontroller provides a decrease in fuel consumption by $17 \%$ and reduces the range of changes in the degree of charge of the traction battery by $35 \%$, and also provides minimization of toxic emissions.

Keywords: electric power plant, hybrid vehicle, technical condition, artificial neural network, storage battery, diagnostics.

\section{Бібліографічне посилання/ Bibliography citation: Harvard}

Bazhinov, O. V., Zaverukha, R. R. and Bazhynova, T. O. (2020) 'Information complex diagnostic system for hybrid and electric vehicles', . Engineering of nature management, (2(16), pp. 12 - 18.

Подано до редакції / Received: 05.08.2020 